\title{
Efficiency of Inspection of Sewer-Pipeline using Mirror Tele-camera System and Sewer-Inspection Support System
}

\author{
Takayoshi OOSAKA \\ Dept. of technological development \\ Tokyo Metropolitan Sewerage Service CO., LTD. \\ 2-6-2,Ootemachi,Chiyoda-ku,Tokyo,100-8699,Japan \\ takayoshi_oosaka@tgs-sw.co.jp \\ Kazunori WATANABE \\ Dept. of city and regional development \\ Nippon Koei CO., LTD. \\ 5-4,Kojimachi,Chiyoda-ku,Tokyo,102-8539,Japan \\ a5737@n-koei.co.jp \\ Kiichiro TOUGOU \\ Dept. of image sensing equipment \\ Toshiba Teli CO., LTD. \\ 4-7-1,Asahigaoka,Hino,Tokyo,191-0065,Japan \\ k-togo@toshiba-teli.co.jp
}

\author{
Takeki KAJIURA \\ Dept. of city and regional development \\ Nippon Koei CO., LTD. \\ 5-4,Kojimachi,Chiyoda-ku,Tokyo,102-8539,Japan \\ a5553@n-koei.co.jp \\ Shinji NUMAO \\ Dept. of systems engineering \\ Nippon Koei CO., LTD. \\ 5-4,Kojimachi,Chiyoda-ku,Tokyo,102-8539,Japan \\ a2767@n-koei.co.jp
}

\begin{abstract}
We developed the Mirror Tele-camera System for efficiency improvement of inspection by TV-camera. And we developed the Sewer Internal-Image Conversion System and the Sewer-Inspection Support System by using the image of the Mirror Tele-camera System. 1) The Mirror Tele-camera System, a camera that can obtain a 360-degree side scan image to improve pipeline inspection and records the internal surfaces of a sewer as images on digital video tape. 2) The Sewer Internal-Image Conversion System, which makes a projection image of a pipeline scanned by the Mirror Tele-camera. 3) The Sewer-Inspection Support System, which is a semi-automated system of diagnosing the damaged points in the pipeline from the projection image. It is likely to be able to contribute to efficiency improvement of sewer-works by effectively using those 3 systems.
\end{abstract}

Keywords: Mirror Tele-camera, conversion, semi-automated inspection

\section{Introduction}

The information of sewer-pipeline had been managed by keeping pictures and maps before information instruments develops.

In this age, it was not attached importance to grasp the present condition of the sewer-pipeline because emphatically expanding spread of sewer-pipeline.

In Tokyo-Metropolitan, it have been attached importance to renew old pipeline, after it reached about $100 \%$ spread of sewer-pipeline in 1994.

It is very important to grasp enough and reflect the present condition of the sewer-pipeline for efficient sewer-pipeline renewal. Inspection of sewer-pipelines provides important basic information for those renewal planning, design, execution, and pipeline maintenance.
Therefore, in Tokyo-Metropolitan, the importance of the inspection of sewer-pipeline have been reaffirmed, and the technology of inspection of sewer-pipelines by TV-camera that applied small diameter pipes and the method of analysis of inspection data have been developed.

\section{The problems of inspection of sewer-pipelines}

Now, the problems of inspection of sewer-pipelines by TV-camera are :

(1) From the inspection

(1) The difference of the performance of TV-cameras and skill of the operators cause the difference of the inspection results.

(2) The shade is rough, and the resolution of image is low from the analog video tape, therefore it causes to 
overlook detailed damaged points.

(3) When detecting damaged point in conventional method, it is necessary to stop running of camera temporarily and observe in detail, so it takes a long time to inspect.

(2) From the information management

(1) It takes a long time to retrieve inspection information because the inspection images are collected to videotapes.

(2) It is difficult to grasp whole images of the sewer-pipelines because image data and character data are separately kept.

\section{Description of the New Inspection Procedure}

To solve those problems, we have been collaborating since the year 2000. We have developed a new procedure for inspection of pipelines: the Mirror Tele-camera System, the Sewer Internal-Image Conversion System, and the Sewer-Inspection Support System.

\subsection{The Mirror Tele-camera System}

In conventional method, when damaged points are discovered, the camera operator must stop the camera and pan the camera to point at the side-wall to capture the image of the damaged point. In this method, it is impossible to obtain the image of side view, so we cannot help relying on the experience for the judgment of degree of damage. Our Tele-camera System simultaneously captures both the forward looking image and the side scan image as the camera advances straight ahead. (Figure 1) shows the image-capture area of the Tele-camera System.

\section{Area of side view}

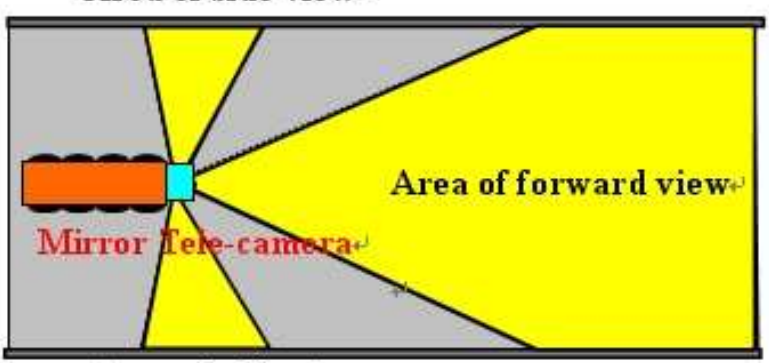

Area of side view

Figure 1. Image-capture area of Mirror-Tele-camera

The Mirror Tele-camera System (Figure 2) can obtain a 360-degree side scan and forward image view automatically as the Tele-camera travels straight at a fixed speed inside a pipeline. Therefore it is possible to reduce the field-time required for image recording (Table 1).

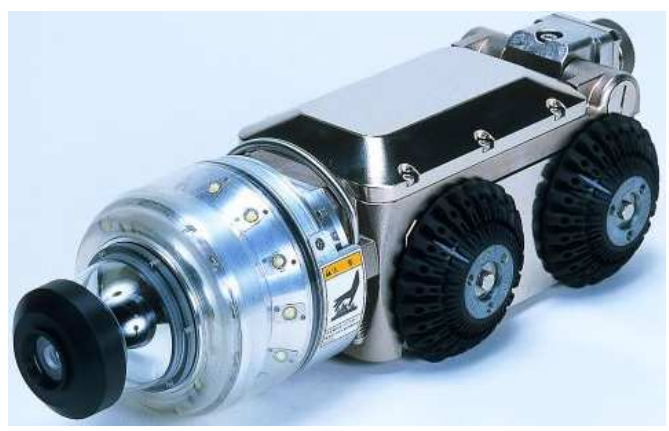

Figure 2. Mirror Tele-camera

Table1. Comparison of Recording Time in the field for Mirror Tele-camera and Conventional Lens Camera (Inspected Distance: 7 spans; 330 m) (Unit: minutes)

\begin{tabular}{|c|c|c||}
\hline $\begin{array}{c}\text { Work } \\
\text { Component }\end{array}$ & $\begin{array}{c}\text { Normal-Lens } \\
\text { Tele-camera } \\
\text { System }\end{array}$ & $\begin{array}{c}\text { Mirror } \\
\text { Tele-camera } \\
\text { System }\end{array}$ \\
\hline \hline Preparation & 132 & 84 \\
\hline $\begin{array}{c}\text { Inspection of } \\
\text { Pipeline }\end{array}$ & 214 & 62 \\
\hline $\begin{array}{c}\text { Recovery of } \\
\text { System }\end{array}$ & 83 & 59 \\
\hline \hline Total Time & 429 & 205 \\
\hline
\end{tabular}

\subsection{The Sewer Internal-Image Conversion System}

The Sewer Internal-Image Conversion-System converts video footage of the internal surface of a pipeline recorded by the Mirror Tele-camera System to a digital 2-D projection image (Figure 3 ).

This streamlines the inspection work and enables the inspection data to be used effectively. All digital data are stored in a database on a personal computer. We can easily search the database to display the digital data as an inspection report (Figure 4) or edit it. In addition, the system can create tabulations of damaged points in the pipeline from the inspection report. With traditional methods, when we inspect a pipeline using an analog camera, the results of the inspection are stored as video-tapes and hard copy. The database system dramatically reduces the time for searching for damage points. When we come to repair the pipeline, we can efficiently grasp the detailed pipeline conditions from the database. 

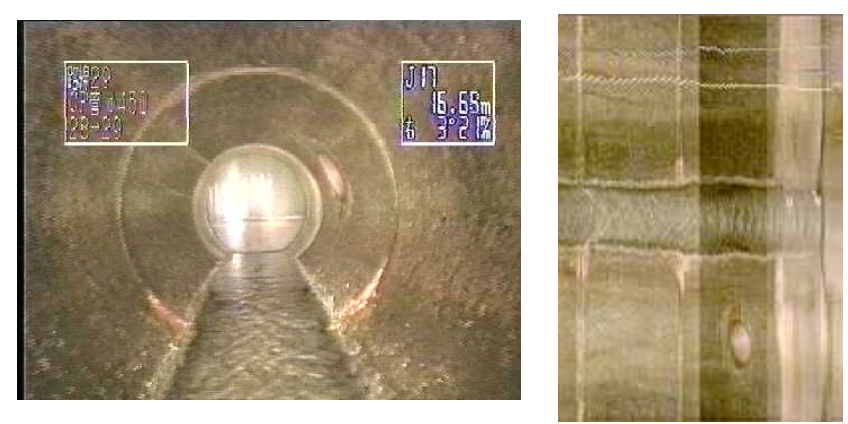

Figure 3. Video image and conversion image

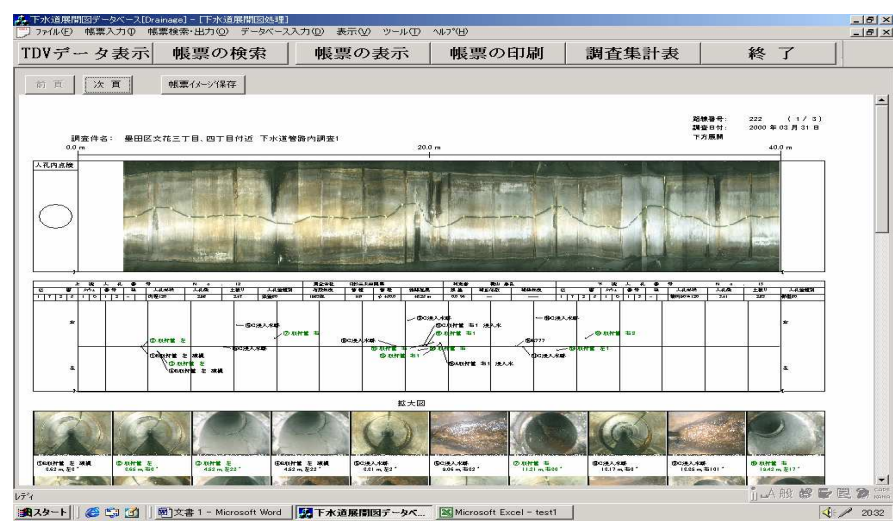

Figure 4. Sewer Pipeline Inspection Report

\subsection{The Sewer-Inspection Support System}

The Sewer-Inspection Support System is software that semi-automatically diagnoses the damaged points from the forward and side scan images of the internal surfaces of a pipeline recorded on video-tapes from the Mirror Tele-camera System. We have developed various image processing algorithms for the Sewer-Inspection Support System. Using these algorithms, we can identify the damaged points in the pipeline automatically.

We compared the diagnostic time of the present procedure with the diagnostic time of the Sewer-Inspection Support System (Table 2). We found that the diagnostic time with the new system is only $10 \%$ of that with the conventional system. The Sewer-Inspection Support System can pick up all damaged points in a pipeline, but it also records false positives, i.e., it mistakenly identifies damage points where there are none. The total number of identified damaged points may be as much as 7-8 times the actual damage points. Therefore, a human operator must re-examine all identified damaged points on the image and re-classify any false positives. The diagnosis time of the new procedure shown in Table 2 excludes the time for inspecting and re-classifying non-damaged points. With better parameter selection and new algorithms for image processing, we should be able to achieve the ideal diagnosis time shown in Table 2.

Table 2. Comparison of Diagnosis Time for Current and New Procedures.

\begin{tabular}{||c|c|c|c||}
\hline $\begin{array}{c}\text { Diameter of } \\
\text { Pipeline } \\
(\mathrm{mm})\end{array}$ & $\begin{array}{c}\text { Length of } \\
\text { Pipeline } \\
(\mathrm{m})\end{array}$ & $\begin{array}{c}\text { Time for } \\
\text { present } \\
\text { procedure } \\
(\mathrm{mm}: \mathrm{ss})\end{array}$ & $\begin{array}{c}\text { Time for } \\
\text { new } \\
\text { procedure } \\
(\mathrm{mm}: \mathrm{ss})\end{array}$ \\
\hline \hline 250 & 44.50 & $24: 38$ & $2: 41$ \\
\hline 300 & 36.25 & $44: 31$ & $3: 12$ \\
\hline 400 & 46.35 & $25: 09$ & $2: 30$ \\
\hline 450 & 42.50 & $24: 46$ & $2: 22$ \\
\hline 500 & 61.90 & $43: 43$ & $2: 55$ \\
\hline 600 & 46.10 & $23: 13$ & $2: 00$ \\
\hline 700 & 52.10 & $28: 18$ & $4: 17$ \\
\hline
\end{tabular}

\section{Effective use methods of 3 systems}

In Tokyo-Metropolitan, the Sewer Internal-Image Conversion System has been experimentally linked with

$\lceil$ Sewer Mapping Information System (SEMIS)」. In 2 years from 2004 to $2005,55 \mathrm{~km}$ inspection results of sewer-pipelines linked with SEMIS as Conversion image.

The information of sewer-pipelines can be grasped speedy and accurately by overlapping pipeline information data, inspection results, internal-image conversion data.

The effective use methods of 3 systems for sewer-pipeline maintenance are shown based on the example of Tokyo bellow.

4.1 Speed-up of necessary information retrieval by making of sewer-pipeline inspection result database

The past, sewer-pipeline inspection results and images had been retrieved from paper reports and inspected by playing videotapes from the beginning.

However, it is possible to inspect necessary internal-image conversion dates and animation at once by linking the internal-image conversion databases with SEMIS databases. In addition, it is possible to output total tables that have been described to past report, and inspect necessary internal-image conversion data and animation at once by clicking the number on the total table. 
Thus, the time required for the retrieval videotapes and the collation with mapping data can be greatly shortened.

\subsection{Accurate grasp of damaged pipe and planning repair,} improvement, and renewal

The damaged pipeline can be accurately grasped on the map by linking the internal-image conversion databases with SEMIS databases.

So the overall, relative evaluation from the entire object area becomes possible, and this evaluation can be used to repair, improvement, and renewal plan.

\subsection{Update of repair and improvement history to damaged} pipes

If the damaged pipes are repaired or improved based on the sewer-pipeline inspection results, it is impossible to reflect the repair or improvement history and update pipeline database. In addition, this latest information can be share in management office.

\section{Problem and limit of the system, deployment of future}

Problem and limit of the system are that:

In The Sewer-Inspection Support System, though it is possible to almost automatically diagnose remarkable damaged points, it mistakenly identifies minute damage points where there are none, therefore, a human operator must re-examine all identified damaged points on the image and re-classify any false positives.

It is scheduled to improve it to the system that uses it easily more according to the demand of the sewer-pipeline manager who actually utilizes the system as a view in the future.

\section{Conclusion}

We developed a new procedure for inspection of pipelines: the Mirror Tele-camera System, the Sewer Internal-Image Conversion System, and the Sewer-Inspection Support System. These technologies are:

(1) The Mirror Tele-camera System, a camera that can obtain a 360-degree side scan image to improve pipeline inspection and records the internal surfaces of a sewer as images on digital video tape.
(2) The Sewer Internal-Image Conversion System, which makes a projection image of a pipeline scanned by the Mirror Tele-camera.

(3) The Sewer-Inspection Support System, which is a semi-automated system of diagnosing the damaged points in the pipeline from the projection image.

The effects on introduction of these systems are:

(1) The Mirror Tele-camera System doubles the amount of pipeline that can be inspected in a day.

(2) The Sewer Internal-Image Conversion System and Sewer-Inspection Support System diagnose the condition of the pipeline in the office; and finally, the images and inspection results are recorded in a database.

(3) The Sewer Internal-Image Conversion System gives a whole image and overall judgment of the sewer pipeline.

(4) The Sewer Inspection-Support System saves office time in detecting damaged points in a sewer pipeline.

(5) The database system for storing inspection data dramatically improves convenience and reduces time for retrieving inspection information to about one-sixth of the time taken using present procedures. The storage space for videotapes and inspection reports can also be drastically reduced.

(6) The entire new procedure, from pipe inspection through to database storage, involves a similar level of costs to sewer-pipeline inspection within current procedures.

As stated above, we developed the Mirror Tele-camera System for efficiency improvement of inspection by TV-camera. And we developed the Sewer Internal-Image Conversion System and the Sewer-Inspection Support System by using the image of the Mirror Tele-camera System.

Inspection of sewer pipelines provides indispensable, important, and basic information for pipeline construction and maintenance. It is likely to be able to contribute to efficiency improvement of sewer-works by effectively using those 3 systems. 